\title{
Amphiphilic Poly( $\varepsilon$-caprolactone)-Poly(vinyl alcohol) Block Copolymer: Preparation from a Bifunctional Initiator
}

\author{
Jin Zhou, Akinori TaKasu, Yoshihito InAI, and Tadamichi HiRABAYASHI ${ }^{\dagger}$ \\ Department of Environmental Technology and Urban Planning, Graduate School of Engineering, \\ Nagoya Institute of Technology, Gokiso-cho, Showa-ku, Nagoya 466-8555, Japan
}

(Received September 8, 2003; Accepted December 15, 2003)

\begin{abstract}
Synthesis of a new block copolymer, Poly(E-caprolactone)-block-Poly(vinyloxytriethylsilane) (PCL$b$-PVOTES) was examined by using a bifunctional initiator 4-(2-Hydroxyethoxy)benzaldehyde (4-HEBA) or (5Hydroxymethyl)furfural (5-HMF) which was responsive to both living ring-opening polymerization (ROP) and aldol-type group-transfer polymerization (Aldol-GTP). The structures of the resulting block copolymers were confirmed by ${ }^{1} \mathrm{HNMR}$, IR, and size-exclusion chromatography (SEC). Desilylation of this PCL- $b$-PVOTES copolymer by acidic methanol resulted in an aimed amphiphilic block copolymer, namely Poly( $\varepsilon$-caprolactone)-block-Poly(vinyl alcohol) (PCL- $b$-PVA).

KEY WORDS Poly( $\varepsilon$-caprolactone)-block-Poly(vinyloxytriethylsilane) / Poly( $\varepsilon$-caprolactone)block-Poly(vinyl alcohol) / Bifunctional Initiator / Aldol-type Group-Transfer Polymerization (Aldol-GTP) / Ring-Opening Polymerization (ROP) / Amphiphilic Block Copolymer /
\end{abstract}

Recently, there are rapidly growing needs for biodegradable materials for various kinds of applications owing to people's concerns with environmental problems. Many scientists have extensively studied the synthesis and commercialization of aliphatic polyesters mainly because of their potential for providing degradability. ${ }^{1}$ Poly ( $\varepsilon$-caprolactone) (PCL) is one of the biodegradable polyesters responsible to use as both ecological polymer and biomedical polymer. ${ }^{1}$ Furthermore, PCL with a high molecular weight can be formed into fibers or blown films having similar mechanical properties with low-density polyethylene. ${ }^{2}$ However, PCL exhibits a melting temperature close to $60^{\circ} \mathrm{C}$, representing a severe limitation for many daily applications. This weakness might be overcome when a PCL is used together with polymers having high melting point and other excellent physical properties. When such hybrid (co)polymers are achieved, the good biodegradability of PCL can be successfully applied in practice.

Poly(vinyl alcohol) (PVA) is one of water soluble polymers and the only vinyl-type biodegradable synthetic polymer, even though its biodegradation rate under natural environmental conditions is rather slow. ${ }^{3}$ PVA is extensively applied in biomedical field owing to its non-toxicity and excellent biocompatibility. As the simplest way, PVA is often selected to blend with other biodegradable polymers for research. ${ }^{4-7}$ Especially, the flexibility and the hydrophilicity of the brittle polyesters are expected to be improved after blending with PVA. ${ }^{8}$ The morphology of PCL/PVA blends has been studied by David et al. ${ }^{5}$ Concerning the biodegradability, David et al. has reported that even the PCL-rich blends were not degraded by microorganisms from a compost of house-hold refuse, while pure PCL films was completely assimilated over periods of $600-800 \mathrm{~h} .{ }^{9}$ So the synthesis of PCL-PVA block copolymer attracted our attention to expect that they would show different biodegradation behavior from the blends depending on the chain length of two blocks.

Usually, block copolymers are prepared by sequential addition of monomers to single active species or by coupling reaction of the preformed functional polymers. ${ }^{10}$ In our previous work, ${ }^{11}$ we have succeeded in synthesis of $\operatorname{Poly}(\varepsilon$-caprolactone)-blockPoly\{vinyloxy(tert-butyl)dimethylsilane $\}, \quad$ (PCL- $b$ PVOTBDMS), through a coupling method. Each block unit could be prepared by ring-opening polymerization (ROP) of CL and aldol-type group-transfer polymerization (Aldol-GTP) of VOTBDMS, respectively. The aimed PCL- $b$-PVA copolymer could be obtained by desilylation from PVOTBDMS unit in the original block copolymer. In the above case, however, two blocks were bound through a rather unstable semi-acetal structure.

In order to obtain PCL- $b$-PVA copolymer with more stable chemical bond, a new route will be investigated in the present work. As illustrated in Scheme 1, the new synthetic route involves two polymerization processes started from a single initiator responsible to ROP of $\varepsilon$-CL as well as Aldol-GTP of vinyloxytriethylsilane (VOTES). The PCL- $b$-PVA copolymer with a stable chemical bond involving an aromatic ring can

${ }^{\dagger}$ To whom correspondences should be addressed (E-mail: hirabayashi@mse.nitech.ac.jp). 


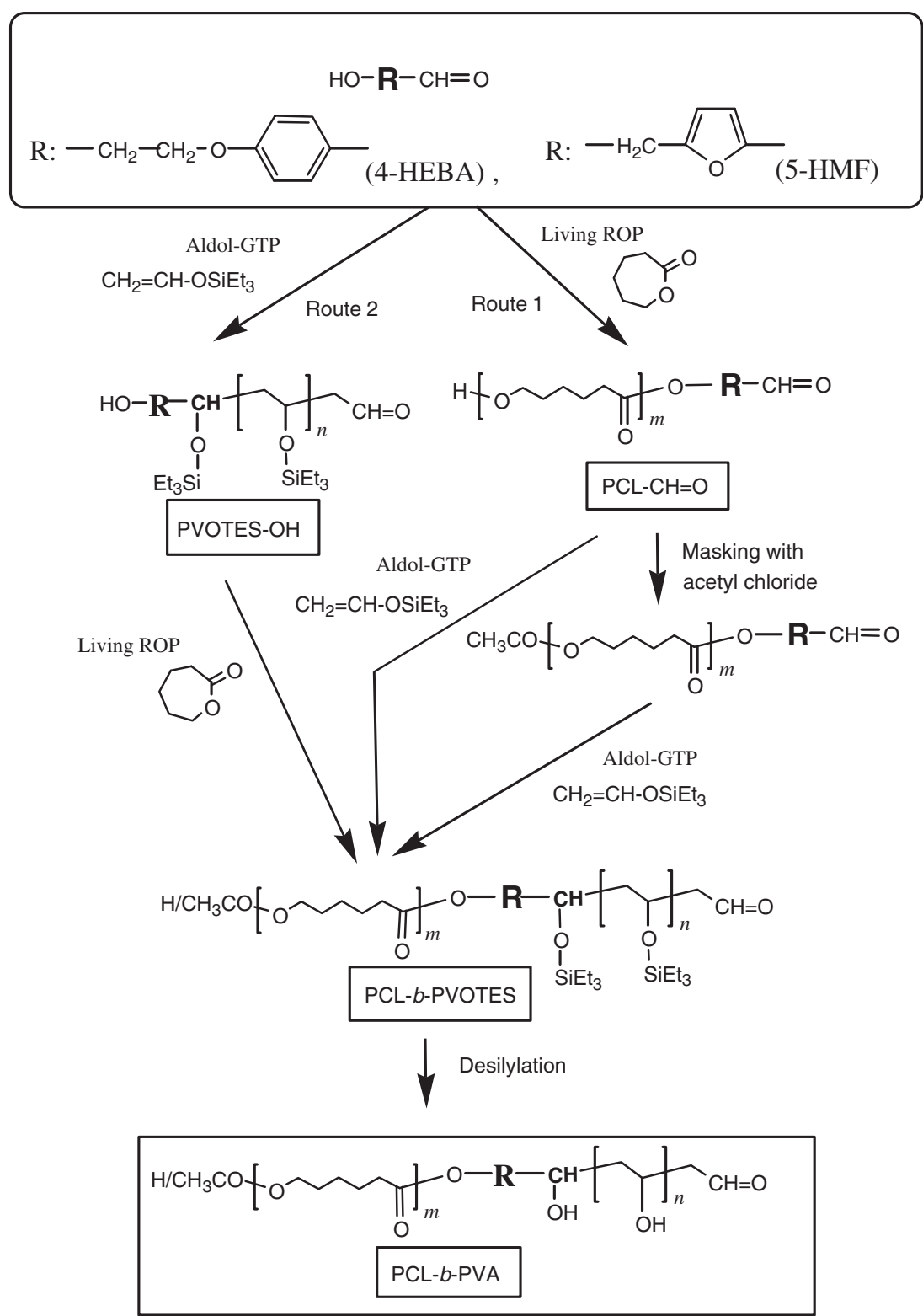

Scheme 1. Approach route for PCL- $b$-PVA copolymer started from a bifunct-ional initiator (4-HEBA or 5-HMF).

be obtained after desilylation with little damage by side reactions.

Although it was well known that the best result in molecular weight regulation was achieved ${ }^{12}$ through Aldol-GTP of VOTBDMS as a monomer, the strong acid condition needed for desilylation of VOTBDMS block often caused hydrolysis of ester linkages in PCL block. We used VOTES as monomer in this work for its compromise between the stability of silyl group during polymerization and easiness for desilylation even though it showed no good regulation in molecular weight as VOTBDMS. As bifunctional initiator, aromatic aldehyde having hydroxyl group must be fit for our purpose. Two types of initiator, benzaldehyde and furfural derivatives are examined in this work. Hydrophilicity, thermal behavior, and biodegradation rate of the PCL- $b$-PVA copolymers must be controlled and balanced by changing the chain length of the two block segments, and new applications may arise from these designed properties.

\section{EXPERIMENTAL}

\section{Materials}

$\varepsilon$-Caprolactone $\left(\varepsilon\right.$-CL) was dried over $\mathrm{CaH}_{2}$ and distilled under reduced pressure just before use. Vinyloxytriethylsilane (VOTES) was synthesized according to the procedure reported by Jung and Blum, ${ }^{13}$ dried over $\mathrm{CaH}_{2}$ for $24 \mathrm{~h}$, and distilled under reduced pressure just before use. Two initiators, 4-(2-hydroxyethoxy)benzaldehyde (4-HEBA) and (5-hydroxymethyl)furfural (5-HMF), as well as stannous octanoate $\left(\mathrm{Sn}(\mathrm{Oct})_{2}\right)$ as a catalyst were commercially available in highly pure state and used without further purification. Zinc bromide $\left(\mathrm{ZnBr}_{2}\right)$ was purified by sublimation just before use. Dichloromethane 
$\left(\mathrm{CH}_{2} \mathrm{Cl}_{2}\right)$, diethyl ether $\left(\mathrm{Et}_{2} \mathrm{O}\right)$, tetrahydrofuran (THF), and toluene were purified by distillation before use.

\section{Measurements}

${ }^{1} \mathrm{HNMR}$ spectra were measured by Bruker DPX200 (200 MHz) spectrometer. Number-average molecular weight $\left(M_{\mathrm{n}}\right)$ and polydispersity index of the molecular weight $\left(M_{\mathrm{w}} / M_{\mathrm{n}}\right)$ were determined by size-exclusion chromatography (SEC) with a series of Tosoh G2000-, G3000-, G4000-, and G5000-HXL columns, used THF as an eluent and calibrated with polystyrene standards. IR spectra were recorded in $\mathrm{KBr}$ disk on a JASCO FT/IR-400 spectrometer.

\section{ROP of $\varepsilon$-CL Initiated by 4-HEBA or 5-HMF}

Initiator 4-HEBA (or 5-HMF) and $\mathrm{Sn}(\mathrm{Oct})_{2}$ dissolved individually in toluene were charged in a dried flask under nitrogen atmosphere. Then the calculated amount of $\varepsilon$-CL monomer according to the predetermined molar ratio to initiator was added to the flask. The polymerization was carried out on an oil-bath at $100^{\circ} \mathrm{C}$. After a prescribed time, the polymer was precipitated from $n$-hexane and dried in vасио to a constant weight.

\section{Acetylation of Hydroxyl End Group of PCL}

In a flame dried three-neck flask, PCL dissolved in THF and excess amounts of triethylamine were added under nitrogen atmosphere. Then excessive acetyl chloride in THF was added dropwise to the above PCL solution under cooling on an ice bath. The reaction mixture was kept stirring at room temperature for $24 \mathrm{~h}$ under nitrogen stream, and then condensed to remove THF partly. After precipitation by pouring the solution into methanol, the product was collected by centrifugation and dried in vacuo to a constant weight.

\section{Aldol-GTP of VOTES Initiated by Formyl-Terminated Macroinitiator PCL}

By using a macroinitiator i.e., formyl-terminated
PCL synthesized above, polymerization of VOTES was carried out under Aldol-GTP conditions. A glass tube with a magnetic stirring chip was flamed and purged-and-filled with nitrogen for three times. Macroinitiator dissolved in $\mathrm{CH}_{2} \mathrm{Cl}_{2}$ and the solution of $\mathrm{ZnBr}_{2}$ in $\mathrm{Et}_{2} \mathrm{O}$ were charged in the glass tube cooled at $-78^{\circ} \mathrm{C}$ under nitrogen atmosphere. Then VOTES was added into the mixture. The polymerization was carried out at $0{ }^{\circ} \mathrm{C}$ with stirring. After the predetermined time, a mixture of methanol and triethylamine $(1: 1 \mathrm{vol})$ was added to make the catalyst inactive. The reaction mixture was precipitated by methanol. The crude polymer was purified by extraction with $n$-hexane so as to remove PVOTES homopolymer. The final product was dried under vacuum at ambient temperature until a constant weight.

\section{Preparation of PCL-b-PVA Copolymer by Desilyla- tion of PVOTES Block}

One hundred milligrams of PCL- $b$-PVOTES copolymer were dissolved in a mixture composed of $10 \mathrm{~mL}$ of THF and $1 \mathrm{~mL}$ of $\mathrm{MeOH}$. Then $1 \mathrm{~N} \mathrm{HCl}$ aqueous solution was added in 1-2 mol\% of VOTES units. After $48-72 \mathrm{~h}$, the precipitate was recovered by pouring reaction solution into $n$-hexane, and dried in vacuo to a constant weight.

\section{RESULTS AND DISCUSSION}

ROP of $\varepsilon$-CL Initiated from 4-HEBA or 5-HMF; Making Formyl-Terminated Macroinitiators $(P C L-C H=O)$

In order to synthesize PCL- $b$-PVOTES copolymer, preparation of macroinitiator $(\mathrm{PCL}-\mathrm{CH}=\mathrm{O})$ having formyl group at its terminal was first investigated in detail. The results are summarized in Table I.

$\mathrm{Sn}(\mathrm{Oct})_{2}$ is one of the most popular and effective catalysts for ROP of various cyclic esters, such as lactide and $\varepsilon$-CL. ${ }^{14}$ The ROP of $\varepsilon$-CL with $\mathrm{Sn}(\mathrm{Oct})_{2}$ as a catalyst and ethanol as an initiator was proved to proceed in living manner. According to Scheme 1, a new type of initiator 4-HEBA or 5-HMF bearing hydroxyl

Table I. Ring-opening polymerization of $\varepsilon$-CL (M) in toluene by using $\mathrm{Sn}(\mathrm{Oct})_{2}$ as a catalyst and 5-HMF or 4-HEBA as an initiator

\begin{tabular}{|c|c|c|c|c|c|c|c|c|c|c|c|c|}
\hline \multirow{2}{*}{$\begin{array}{l}\text { Entry } \\
\text { No }\end{array}$} & \multirow[b]{2}{*}{ Initiator } & \multirow{2}{*}{$\begin{array}{c}{[\mathrm{M}]_{0} /} \\
{[\text { Initiator }]_{0}} \\
(\mathrm{~mol} / \mathrm{mol})\end{array}$} & \multirow{2}{*}{$\begin{array}{c}\text { Catalyst } \\
\text { /M } \\
(\mathrm{mol} \%)\end{array}$} & \multirow{2}{*}{$\begin{array}{l}\text { Temp. } \\
\left({ }^{\circ} \mathrm{C}\right)\end{array}$} & \multirow{2}{*}{$\begin{array}{l}\text { Reaction } \\
\text { time } \\
\text { (h) }\end{array}$} & \multicolumn{5}{|c|}{$\mathrm{HO}-\mathrm{PCL}-\mathrm{CH}=\mathrm{O}$} & \multicolumn{2}{|c|}{$\mathrm{CH}_{3} \mathrm{COO}-\mathrm{PCL}-\mathrm{CH}=\mathrm{O}^{\mathrm{d}}$} \\
\hline & & & & & & $\begin{array}{l}\text { Yield } \\
(w t \%)\end{array}$ & $\begin{array}{c}M_{\mathrm{n}}(\text { Calc. })^{\mathrm{a}} \\
\left(\times 10^{-3}\right)\end{array}$ & $\begin{array}{c}M_{\mathrm{n}}(\mathrm{NMR})^{\mathrm{b}} \\
\left(\times 10^{-3}\right)\end{array}$ & $\begin{array}{c}M_{\mathrm{n}}(\mathrm{SEC})^{\mathrm{c}} \\
\left(\times 10^{-3}\right)\end{array}$ & $M_{\mathrm{w}} / M_{\mathrm{n}}^{\mathrm{c}}$ & $\begin{array}{c}M_{\mathrm{n}}(\mathrm{SEC})^{\mathrm{c}} \\
\times 10^{-3} \\
\end{array}$ & $M_{\mathrm{w}} / M_{\mathrm{n}}{ }^{\mathrm{c}}$ \\
\hline 1 & 5-HMF & 20 & 0.10 & 110 & 24 & 96.20 & 2.32 & 2.75 & 6.38 & 1.43 & 7.15 & 1.31 \\
\hline 2 & 5-HMF & 20 & 0.10 & 90 & 30 & 95.20 & 2.30 & 3.32 & 4.82 & 1.20 & - & - \\
\hline 3 & 4-HEBA & 10 & 0.50 & 90 & 20 & 100.00 & 1.31 & 1.99 & 4.77 & 1.65 & 4.41 & 1.60 \\
\hline 4 & 4-HEBA & 20 & 0.50 & 90 & 20 & 96.10 & 2.36 & 4.16 & 9.22 & 1.79 & 7.82 & 1.89 \\
\hline 5 & 4-HEBA & 30 & 0.35 & 100 & 24 & 97.77 & 3.51 & 6.44 & 10.91 & 1.64 & 12.75 & 1.59 \\
\hline 6 & 4-HEBA & 40 & 0.25 & 90 & 20 & 97.85 & 4.63 & 7.01 & 10.35 & 1.67 & 11.10 & 1.63 \\
\hline
\end{tabular}

${ }^{a}$ Theoretical number-average molecular weight calculated from conversion and $[\mathrm{M}]_{0} /[\text { Initiator }]_{0}$. ${ }^{\mathrm{b}}$ Experimental number-average molecular weight determined by ${ }^{1} \mathrm{H}$ NMR. ${ }^{c}$ Experimental number-average molecular weight and molecular weight distribution as measured by SEC, calibrated by Polystyrene standard. ${ }^{\mathrm{d}}$ Acetylation of hydroxyl end group of $\mathrm{HO}-\mathrm{PCL}-\mathrm{CH}=\mathrm{O}$ by using acetyl chloride. 
group and formyl group simultaneously must be useful for initiating in the ROP of $\varepsilon$-CL. In fact, 5HMF completed the polymerization quantitatively as seen from Entry 1 and 2 in Table I. Lowering reaction temperature from $110^{\circ} \mathrm{C}$ to $90^{\circ} \mathrm{C}$ was helpful to obtain the macroinitiator with more narrow molecular weight distribution. The ${ }^{1}$ H NMR signal of the methylene proton adjacent to furan ring in the polymer was observed at $5.11 \mathrm{ppm}$ and assignable to Furyl$\mathrm{CH}_{2} \mathrm{OCO}$-moiety. Clear shift from $4.70 \mathrm{ppm}$ in 5-HMF itself (Furyl- $\mathrm{CH}_{2} \mathrm{OH}$ ) demonstrated that 5-HMF acted effectively as initiator for the ROP of $\varepsilon$-CL. The intensity ratio of the formyl proton signal at $9.62 \mathrm{ppm}$ and the two proton signals on the furan ring at 7.26 and $6.56 \mathrm{ppm}$ in ${ }^{1} \mathrm{HNMR}$ spectrum was $1: 1: 1$ in turn, verifying that the formyl group was compatible with ROP without any structural damage.

In the case of using 4-HEBA initiator, the molar ratios of $\varepsilon$-CL and 4-HEBA (M/I) were changed to obtain PCL with different molecular weights. Independent from the M/I ratios, the yields were always more than $96 \%$ after the predetermined reaction time. However the $M_{\mathrm{n}}$ values calculated from ${ }^{1} \mathrm{H}$ NMR spectra were somewhat higher than the theoretical ones. It can be explained by the fact that 4-HEBA showed no good miscibility with the solvent (toluene), leading to lower the initiator efficiency. Polar solvents have good miscibility, but made the catalyst for ROP inactive. In this work, toluene was suitable as a solvent also from the standpoint that rather high temperature was required to activate $\mathrm{Sn}(\mathrm{Oct})_{2}$. The ${ }^{1} \mathrm{H}$ NMR spectrum of the purified polymer showed the intensity ratio of the signals assignable to the terminal methylene proton $\left(-\mathrm{CH}_{2} \mathrm{OH}\right)$ in the PCL chain and the aromatic proton (doublet at $7.81 \mathrm{ppm}$ ) adjacent to formyl group was equal to $1: 1$. It demonstrated that all the PCL were initiated from 4-HEBA. Furthermore, the intensity ratio of the signal attributed to formyl group at $9.89 \mathrm{ppm}$, one doublet aromatic proton signal at $7.81 \mathrm{ppm}$, and another aromatic proton signal (doublet at $6.89 \mathrm{ppm}$ ) was kept 1:2:2 after polymerization, proving that no change occurred on the formyl end group of PCL in the course of polymerization. Since formyl-terminated macroinitiators were prepared successfully as described above, our attention was then focused on whether Aldol-GTP of VOTES with such macroinitiators took place smoothly or not.

\section{Aldol-GTP of VOTES Initiated by Formyl-Terminated Macroinitiator $(\mathrm{PCL}-\mathrm{CH}=\mathrm{O})$}

Considering that de-protection of silyl groups will be carried out eventually to obtain the aimed PCL$b$-PVA copolymer, we used VOTES as monomer in this work because it has been examined by us that VOTES showed good compromise between the chem- ical stability of silyl groups during Aldol-GTP and easiness to desilylation. ${ }^{15}$ The occurrence of hydrolysis of the ester linkages in PCL unit can be restrained owing to the mild condition for desilylation from the PVOTES unit.

Although $\mathrm{ZnCl}_{2}, \mathrm{SnCl}_{4}, \mathrm{Sc}(\mathrm{OTf})_{3}, \mathrm{Yt}(\mathrm{OTf})_{3}$ and so on were known as the catalyst for Aldol-GTP, $\mathrm{ZnBr}_{2}$ is proved to be the most suitable catalyst for VOTES via Aldol-GTP. ${ }^{15,16}$ Therefore $\mathrm{ZnBr}_{2}$ solution in $\mathrm{Et}_{2} \mathrm{O}$ was employed as a catalyst in this work, too. $\mathrm{Et}_{2} \mathrm{O}$ has to add to keep the reaction system homogeneous.

The results of polymerization initiated from two types of macroinitiators (formyl-terminated PCLs with various chain lengths) were summarized in Table II. The crude polymers could be obtained by precipitation from polymerization mixture into $\mathrm{MeOH}$ as a non-solvent. Although these copolymers were contaminated with a VOTES homopolymer generated unexpectedly, the homopolymer could be completely removed by reprecipitation with $n$-hexane as a good solvent for PVOTES homopolymer. The SEC profile for the purified block copolymer showed a single peak with rather narrow distribution, which was different in elusion time from the original macroinitiator, indicating no existence of PVOTES homopolymer. The signals attributed to both PCL and PVOTES chains were appeared in the ${ }^{1} \mathrm{HNMR}$ spectrum of the purified polymer, verifying the formation of the aimed block copolymer. The relative molar ratio of the two monomer units of $\varepsilon$-CL and VOTES was determined by ${ }^{1} \mathrm{H}$ NMR spectrum as shown in Table II. The degree of polymerization (DP) of the PVOTES block was calculated by the signal intensity of $\mathrm{Si}\left(\mathrm{CH}_{2} \mathrm{CH}_{3}\right)_{3}$ at $0.60 \mathrm{ppm}$ versus proton signals due to the furan or benzene skeleton in the macroinitiator.

Figure 1 showed the block copolymer initiated from benzaldehyde-type PCL. There were not any remaining signals at $9.88 \mathrm{ppm}$ due to initiating aromatic formyl proton and $7.81 \mathrm{ppm}$ assignable to aromatic proton adjacent to the aromatic formyl end group. A new signal appeared at 7.26 instead of $7.81 \mathrm{ppm}$ indicated that all the formyl groups in the macroinitiator had been consumed to build up the block copolymer. In other words, this ${ }^{1} \mathrm{H}$ NMR spectrum also taught us that the original macroinitiator (i.e. formyl-terminated PCL) was never existence with the purified block copolymer. It was also confirmed in the case of using furfural-type PCL macroinitiator.

The polymerization behaviors of VOTES initiated from two kinds of macroinitiators were compared under the same conditions. It was found that the DP of PVOTES block initiated from benzaldehyde-type PCL (Entry 9) was more superior to that initiated from furfural-type PCL (Entry 7). Since it has been well known that the existence of the electron-donating 
Table II. Aldol-GTPa of VOTES (M) initiated from formyl-terminated PCL (I), in the presence of $\mathrm{ZnBr}_{2} / \mathrm{Et}_{2} \mathrm{O}$ catalyst

\begin{tabular}{|c|c|c|c|c|c|c|c|c|c|c|c|}
\hline \multirow{3}{*}{$\begin{array}{l}\text { Entry } \\
\text { No }\end{array}$} & \multicolumn{2}{|c|}{ Macroinitiator (I) } & \multirow{3}{*}[\mathrm{M}]{$_{0} /[\mathrm{I}]_{0}$} & \multirow{3}{*}[\mathrm{ZnBr}_{2}]{$_{0} /[\mathrm{I}]_{0}$} & \multirow{3}{*}{$\begin{array}{l}\text { Yield }^{\mathrm{d}} \\
(\mathrm{wt} \%)\end{array}$} & \multicolumn{6}{|c|}{ Purified block copolymer } \\
\hline & \multirow{2}{*}{ Type $^{\mathrm{b}}$} & \multirow{2}{*}{$\begin{array}{c}M_{\mathrm{n}} \text { of } \mathrm{PCL}^{\mathrm{c}} \\
\left(\times 10^{-4}\right)\end{array}$} & & & & $M_{\mathrm{n}}^{\mathrm{e}}$ & $M_{\mathrm{w}} / M_{\mathrm{n}}^{\mathrm{e}}$ & \multicolumn{2}{|c|}{ PVOTES block } & \multirow{2}{*}{$\begin{array}{l}\text { PCL block } \\
\operatorname{DP}_{\text {obs }}{ }^{f}\end{array}$} & \multirow{2}{*}{$\begin{array}{l}\text { PVOTES/PCL } \\
(\mathrm{mol} \% / \mathrm{mol} \%)^{\mathrm{f}}\end{array}$} \\
\hline & & & & & & $\left(\times 10^{-4}\right)$ & & $\mathrm{DP}_{\mathrm{obs}}{ }^{\mathrm{f}}$ & $\mathrm{DP}_{\text {calc }^{\mathrm{g}}}^{\mathrm{g}}$ & & \\
\hline 7 & $\mathrm{~F}$ & 0.64 & 60 & 3 & 17.9 & 0.68 & 1.31 & 7 & 36 & 33 & $17.5 / 82.5$ \\
\hline 8 & FA & 0.72 & 80 & 3 & 33.5 & 0.92 & 1.30 & 6 & 52 & 45 & $11.8 / 88.2$ \\
\hline 9 & $\mathrm{~B}$ & 0.92 & 80 & 3 & 13.4 & 1.14 & 1.26 & 15 & 38 & 42 & $26.3 / 73.7$ \\
\hline 10 & B & 1.09 & 80 & 3 & 44.5 & 1.37 & 1.48 & 17 & 40 & 80 & $17.5 / 82.5$ \\
\hline 11 & BA & 1.28 & 80 & 3 & 47.4 & 1.57 & 1.38 & 19 & 36 & 89 & $17.6 / 82.4$ \\
\hline 12 & $\mathrm{BA}$ & 1.11 & 60 & 3 & 47.6 & 1.39 & 1.37 & 12 & 30 & 81 & $12.9 / 81.1$ \\
\hline 13 & BA & 1.11 & 40 & 3 & 52.4 & 1.31 & 1.40 & 8 & 16 & 74 & $9.8 / 91.2$ \\
\hline 14 & BA & 1.11 & 60 & 1 & 48.2 & 1.37 & 1.39 & 9 & 29 & 72 & $11.1 / 88.9$ \\
\hline 15 & BA & 1.11 & 80 & 10 & 36.3 & 1.25 & 1.41 & 10 & 38 & 69 & $12.7 / 87.3$ \\
\hline 16 & $\mathrm{BA}^{\mathrm{h}}$ & 1.11 & 80 & 10 & 45.3 & 1.24 & 1.41 & 6 & 16 & 62 & $8.8 / 91.2$ \\
\hline 17 & $\mathrm{BA}^{\mathrm{i}}$ & 1.11 & 80 & 10 & 37.6 & 1.33 & 1.39 & 8 & 32 & 72 & $10.0 / 90.0$ \\
\hline 18 & $\mathrm{BA}^{\mathrm{j}}$ & 1.11 & 80 & 3 & 42.6 & 1.16 & 1.45 & 9 & 42 & 73 & $11.0 / 89.0$ \\
\hline
\end{tabular}

${ }^{\mathrm{a}}$ General conditions of Aldol-GTP; solvent: $\mathrm{CH}_{2} \mathrm{Cl}_{2}$, temp: $0{ }^{\circ} \mathrm{C}$, time: $120 \mathrm{~h},[\mathrm{M}]_{0}: 1.0 \mathrm{~mol} / \mathrm{L}$ except for Entry 8, 9 , $(1.5 \mathrm{~mol} / \mathrm{L}) .{ }^{\mathrm{b}} \mathrm{F}-$

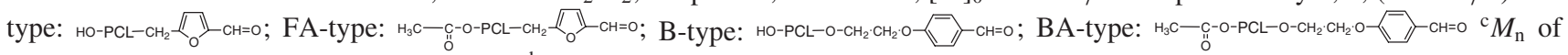
PCL macroinitiator was measured by SEC. ${ }^{d}$ weight percentage of the copolymer recovered after purification by $n$-hexane, based on the total weight of PCL and VOTES monomer in the feed. ${ }^{e}$ Determined by SEC method in THF, calibrated by polystyrene standards. ${ }^{\mathrm{f}}$ Determined by ${ }^{1} \mathrm{H}$ NMR based on aromatic protons in the initiator-moiety. ${ }^{\mathrm{g}}$ Theoretical DP, calculated from the molar ratio of monomer to initiator and monomer conversion. ${ }^{\mathrm{h}}$ Entry 16 : Time: $120 \mathrm{~h},[\mathrm{M}]_{0}: 0.5 \mathrm{~mol} / \mathrm{L}$. ${ }^{\mathrm{i}}$ Entry 17: Time: $284 \mathrm{~h},[\mathrm{M}]_{0}: 0.5 \mathrm{~mol} / \mathrm{L} .{ }^{\mathrm{j}}$ Entry 18 : Time: $284 \mathrm{~h},[\mathrm{M}]_{0}: 0.5 \mathrm{~mol} / \mathrm{L}$.

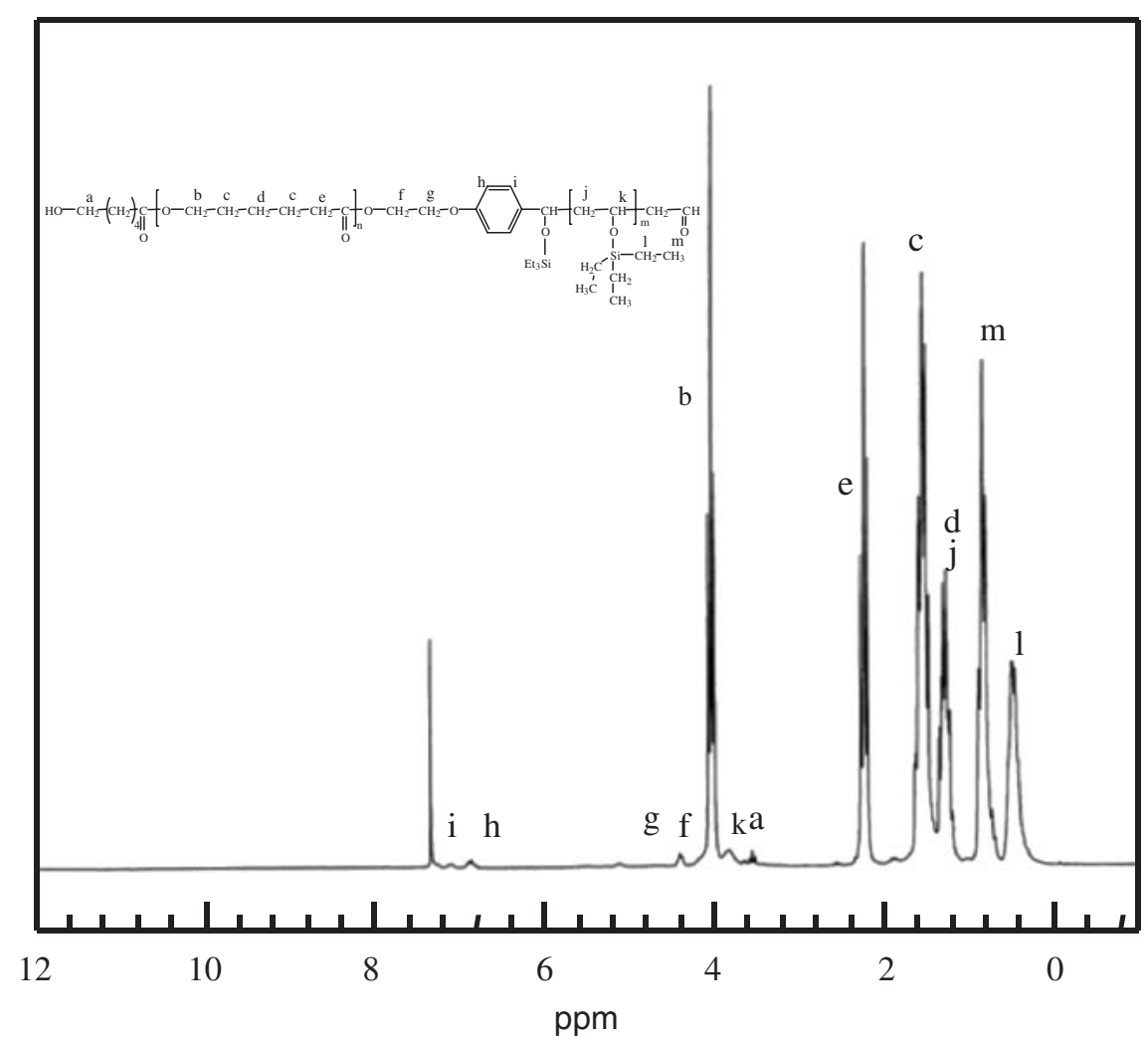

Figure 1. ${ }^{1} \mathrm{H}$ NMR spectrum of PCL- $b$-PVOTES copolymer (Entry 9, Table II) measured in $\mathrm{CDCl}_{3}$ at $25^{\circ} \mathrm{C}$.

group at the $p$-position in the benzaldehyde accelerates the initiation of Aldol-GTP, ${ }^{17}$ the higher ability of our benzaldehyde-type macroinitiator is reasonable even if the formyl end group might be buried inside the PCL matrix. In the furfural type initiator, however, oxygen in the furan ring tends to make the 5-men- bered chelate structure involving $\mathrm{ZnBr}_{2}$ coordinated by the formyl end group. This stable chelate (1) induces to lower Lewis acidity of $\mathrm{ZnBr}_{2}$ and obstructs the smooth migration of catalyst toward the new active end (2), as is shown in Scheme 2. As a result, lots of termination reaction must occur in the very early 


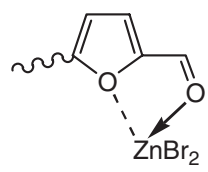

(1)

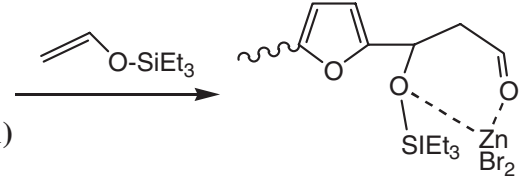

Scheme 2. Aldol-GTP of VOTES initiated from a furfuralterminated PCL-macroinitiator.

stage of the polymerization.

The DPs of the PVOTES block calculated from ${ }^{1} \mathrm{HNMR}$ in all the entries as shown in Table II were lower than the theoretical ones. It can be ascribed to the competitive side reactions to the formation of VOTES homopolymer which was recovered from the supernatant fraction on the treatment of crude products by $n$-hexane. The formation of acetaldehyde via reaction between a hydroxyl end group in the PCL-macroinitiator and $\mathrm{ZnBr}_{2}$ should be considered to contribute to it, as is shown in Scheme 3. Acetaldehyde must be active enough to initiate Aldol-GTP of VOTES. In order to remove such an undesirable effect of the $\mathrm{OH}$ end group, the PCL-macroinitiator was treated with acetyl chloride. The successful acetylation of the $\mathrm{OH}$ end group in the macroinitiator was confirmed by ${ }^{1} \mathrm{HNMR}$ and the $M_{\mathrm{n}}$ values measured by SEC were listed in Table I.

For acetylated benzaldehyde-type macroinitiator (Entry 12), the yield of VOTES homopolymer clearly decreased as compared with Entry 11. Therefore the acetoxy-modified PCL-macroinitiator was employed in the subsequent experiments (Entry 13-17). After excluding the negative influence of the $\mathrm{OH}$ end group of PCL-macroinitiator, the still generated VOTES homopolymer may be reasoned by using excess amounts of catalyst. Also, it was referred that the use of excess amounts of catalyst promoted the formation of VOTES homopolymer. ${ }^{18}$ As more reliable reason, however, the formyl-terminated PCL as macroinitiator itself possibly gave negative effect on the Aldol-GTP of VOTES. In comparison with the typical low molecular weight initiator such as $p$-anisaldehyde, PCL-substituted aromatic aldehyde was inferior as the initiator and therefore might allow some competitive reactions to form the VOTES homopolymer. A main side reaction would be cationic polymerization of vinyl ether monomers. GTP by way of the initiator generated in situ could not be eliminated completely. For example, the formation of acetaldehyde is known to result from the hydrolysis of VOTES by a trace of water in the system. Indeed, VOTES homopolymer can be obtained without any addition of initiator under the similar conditions with Aldol-GTP.

Now, the influence of the long-chain PCL macroinitiator upon the second polymerization manner should be discussed. There will be no suspicion for the presumption that the PCL long chain gave effect to lower Lewis acidity of $\mathrm{ZnBr}_{2}$ due to the coordination with a lot of ester groups. Taking this into account, the suitable amount of catalyst was checked in this work. It is very interesting to find that there is no outstanding difference in the results of the experiments setting a molar ratio of $\mathrm{ZnBr}_{2}$ to formyl end group as 1-3. This result is similar to that in a conventional Aldol-GTP using low molecular aldehyde as the initiator, for example $p$-anisaldehyde. However, against our expectation, 10 times amount of $\mathrm{ZnBr}_{2}$ to formyl end group (Entry 15) resulted in lowering the conversion of the monomer into PVOTES block chain and furthermore tended to shorten somewhat PCL block length. In this case, the excessive catalyst appeared to accelerate the side reactions rather than the Aldol-GTP.

As compared the results of Entry 9 and 10 in Table II by using PCL-macroinitiators with different chain lengths, there is no obvious decrease in the chain length of PVOTES block. It means that we can use PCL with optional chain length to satisfy the practical needs. The chain length of the two block segments must decide the solubility of the block copolymers in $n$-hexane. The block copolymers composed of a short PCL block will be dissolved in $n$-hexane. The low yield of block copolymer reprecipitated from $n$-hexane was rationalized by this reason (Entry 9). The bimodal profile in the SEC and ${ }^{1} \mathrm{H}$ NMR spectrum of polymers obtained from the supernatant in En-

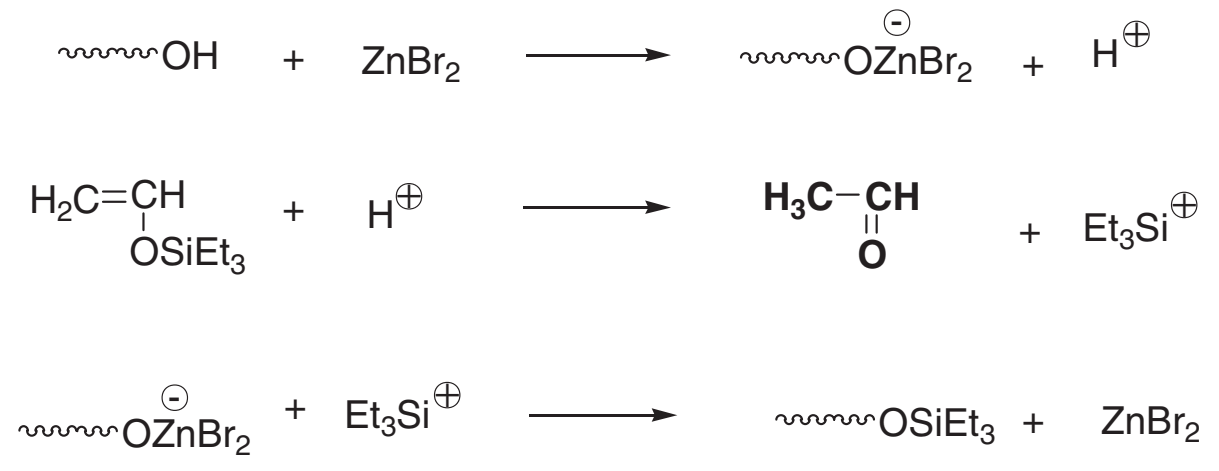

Scheme 3. The reaction proposed to generation of acetaldehyde due to the $\mathrm{OH}$ end group of PCL macroinitiator. 
try 9 indicated the coexistence of block copolymer and PVOTES homopolymer. Some of the block copolymer can be isolated on dealing with the supernatant by 2-propanol. On the other hand, the macroinitiator with long PCL chain can supply the complete block copolymer through only reprecipitation from $n$-hexane.

In order to optimize conditions for the second polymerization, the concentration of the PCL-macroinitiator in the polymerization mixture was varied. No matter of the amount of the catalyst used, the convention of monomer into block copolymer was decreased with dilution by $\mathrm{CH}_{2} \mathrm{Cl}_{2}$ even if the reaction time was prolonged (Entry 16-18 in Table II). Moreover, it was found that the prolonged reaction time resulted in the formation of PVOTES homopolymer rather than block copolymer. The content of PVOTES block increased with increasing the initial concentration of the VOTES monomer, as is demonstrated by Entry 11-13.

\section{Alternative Route to PCL-b-PVOTES Copolymer}

As an alternative route to synthesize PCL- $b$ PVOTES copolymer, two kinds of polymerization processes, ROP and Aldol-GTP, were examined in reverse sequence. That is, Aldol-GTP of VOTES was first carried out in the presence of 4-HEBA or 5HMF as an initiator. Subsequently, hydroxyl-terminated PVOTES obtained from the first step was reacted with $\varepsilon$-CL at $100^{\circ} \mathrm{C}$ using $\mathrm{Sn}(\mathrm{Oct})_{2}$ as a catalyst. The hydroxyl-terminated PVOTES was expected to behave as a macroinitiator in the second step (i.e. ROP of $\varepsilon-\mathrm{CL}$ ). The molar ratio of $\varepsilon$-CL to hydroxyl group in the macroinitiator was set as 30 .

However, bimodal peaks were observed in the SEC profile of the polymer precipitated from $\mathrm{MeOH}$ after the second step, indicating the existence of the unreacted PVOTES macroinitiator. This macroinitiator could be removed by reprecipitation from $n$-hexane and separated from the true block copolymer, i.e. PCL- $b$-PVOTES copolymer. On the basis of these da$\mathrm{ta}$, it is convinced that Aldol-GTP of VOTES with a bifunctional initiator, 4-HEBA or 5-HMF, led to not only the hydroxyl-terminated PVOTES macroinitiator but also the OH-free PVOTES homopolymer because of the reactivity of hydroxyl group itself toward VOTES monomer. The OH-free PVOTES cannot play a role as the macroinitiator on the occasion of the ROP step. Consequently, the apparent efficiency of the macroinitiator involved OH-free PVOTES must be evaluated lower.

Based on the peak intensity of the two blocks in their ${ }^{1} \mathrm{H}$ NMR spectrum, the content of VOTES unit in the remained block copolymer was evaluated as only $4-6 \mathrm{~mol} \%$ no matter of the amount of the catalyst.
The DP of the PCL block must be estimated also by the ${ }^{1} \mathrm{HNMR}$, comparing to the intensity ratio of repeating methylene signal of PCL at $2.3 \mathrm{ppm}$ and aromatic proton signals of initiator-moiety. However this DP value was far larger than that measured by SEC. By way of careful observation of the SEC profile, it was found that peaks due to the PCL homopolymer were overlapped with the peak of block copolymer. It was examined by us that a PCL homopolymer $\left(M_{\mathrm{n}}=2.743 \times 10^{4}, M_{\mathrm{w}} / M_{\mathrm{n}}=1.96\right)$ can be formed without addition of initiator. The relatively weak reactivity of PVOTES derived hydroxyl end group allowed the side reaction to PCL homopolymer occur.

Appropriate masking of $\mathrm{OH}$ end group is required to improve this serious situation. However it is necessary to keep the chemical stability in the course of Aldol-GTP and to be easily eliminated on regenerating the $\mathrm{OH}$ end group responsible for ROP. Unfortunately we cannot find yet the best method to satisfy above two requirements in masking $\mathrm{OH}$ end group. Thus there is little possibility for preparing PCL- $b$ PVOTES copolymer along the route 2 in Scheme 1.

\section{Preparation of PCL-b-PVA Copolymer by Desilyla- tion of PCL-b-PVOTES Copolymer}

In order to avoid the hydrolysis of the ester linkages in PCL block on occasion of desilylation, it is very important to control the added amounts of $\mathrm{MeOH}$ and $\mathrm{HCl}$ aqueous solution ( $\mathrm{HCl}$ aq). The DP of PCL block after desilylation decreased with the increasing amount of $\mathrm{HCl}$ aq. The complete cleavage of silyloxyl groups could be confirmed by disappearance of $\mathrm{Si}\left(\mathrm{CH}_{2} \mathrm{CH}_{3}\right)_{3}$ signals from ${ }^{1} \mathrm{HNMR}$. The formation of PCL- $b$-PVA copolymer was also confirmed by IR spectrum through the appearance of a strong and broad band at $3390 \mathrm{~cm}^{-1}$ assignable to hydroxyl groups on the newly generated PVA block.

With increasing PVA content, the block copolymer became to show poor solubility in good solvents for PCL such as $\mathrm{CHCl}_{3}$, THF etc., while became to dissolve in DMSO at $40^{\circ} \mathrm{C}$. Sometimes the PCL- $b$ PVA copolymer insoluble in DMSO at $40^{\circ} \mathrm{C}$ nevertheless having higher PVA contents was obtained. Probably it was resulted from partial-gelation via etherification described as Scheme 4. The drastic change in their solubility of resulting copolymers must be another evidence for the combination of the two block units.

In order to assure their biodegradability, the block copolymers prepared in this work should be designed in such a way that that the PCL-component could be predominant. In this work, the authors can propose the reliable synthetic method for PCL- $b$-PVA copolymers with the controlled ratios of two block units. Though the biodegradability of PCL- $b$-PVA copoly- 

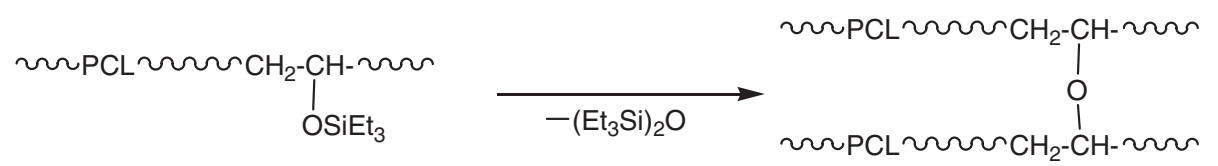

Scheme 4. Presumption to the occurrence of partial-gelation via Etherification during desilylation.

mers will be reported in details in our next paper, it can be noted in brief that the biodegradability was suddenly lost to the block copolymer in which the PVA content exceeded some level (about $25 \mathrm{~mol} \%$ ). Also, the biodegradation behaviors of these copolymers were different from that of a simple blend of PCL and PVA.

\section{CONCLUSIONS}

A new PCL- $b$-PVA copolymer linked through a stable covalent bond was successfully synthesized. Starting from a bifunctional initiator, two different polymerization methods, ROR of $\varepsilon$-CL and Aldol-GTP of VOTES, were put into practice in turn. The first polymer, formyl-terminated PCL, was used as a macroinitiator for Aldol-GTP. An aimed block copolymer, PCL- $b$-PVA, was achieved after the desilylation reaction of PCL- $b$-PVOTES copolymer. It is one of the reasons for our successful arrival at the goal to employ VOTES as monomer in this work. This monomer was known to be slightly less in hydrolytic stability during Aldol-GTP process than vinyloxy-tert-butyldimethylsilane (VOTBDMS). However, desilylation from this PVOTES block was allowed to conduct under mild conditions and it is very helpful to avoid hydrolysis of ester linkage in PCL chain during desilylation. The formyl end group involving in the initiator did not prevent ROP of $\varepsilon$-CL, while the hydroxyl end group brought about many negative influences on the Aldol-GTP of VOTES. Therefore ROP of $\varepsilon$-CL should be done ahead of Aldol-GTP of VOTES. Two types of formyl-terminated PCL macroinitiator initiated from 4-HEBA and 5-HMF were prepared in this report. The PCL-macroinitiator with benzene ring at the terminal (i.e. benzaldehyde-type) is preferable to that with furan ring (furfural-type) for occurrence of Aldol-GTP.

\section{REFERENCES}

1. Y. Ikada and H. Tsuji, Macromol. Rapid Commun., 21, 117 (2000).

2. G. Seretoudi, D. Bikiaris, and C. Panayiotou, Polymer, 43, 5405 (2002).

3. S. Gartiser, M. Wallrabestein, and G. Stiene, J. Environ. Polym. Degrad., 6, 159 (1999).

4. T. Ikejima, A. Cao, N. Yoshie, and Y. Inoue, Polym. Degrad. Stab., 62, 463 (1998).

5. C. D. Kesel, C. Lefevre, J. B Nagy, and C. David, Polymer, 40, 1969 (1999).

6. M. L. Young, H. K. Su, and J. K. Seon, Polymer, 37, 5897 (1996).

7. K. Aoi, A. Takasu, and M. Okada, Macromolecules, 30, 6134 (1997).

8. X. T. Shuai, Y. He, N. Asakawa, and Y. J. Inoue, Appl. Polym. Sci., 81, 762 (2001).

9. C. D. Kesel, C. V. Wauven, and C. David, Polym. Degrad. Stab., 55, 107 (1997).

10. M. Trollsås, J. L. Hedrick, Ph. Dubois, and R. Jérôme, J. Polym. Sci., Part A: Polym. Chem., 36, 1345 (1998).

11. J. Zhou, A. Kaga, A. Takasu, Y. Inai, and T. Hirabayashi, Polym. J., 35, 757 (2003).

12. D. Y. Sogah and O. W. Webster, Macromolecules, 19, 1775 (1986).

13. M. E. Jung and R. B. Blum, Tetrahedron Lett., 43, 3791 (1977).

14. A. Schindler, Y. M. Hibionada, and C. G. Pitt, J. Polym. Sci., Part A: Polym. Chem., 20, 319 (1982).

15. A. Takasu, S. Ohmori, Y. Yamauchi, and T. Hirabayashi, J. Polym. Sci., Part A: Polym. Chem., 40, 4477 (2002).

16. T. Hirabayashi, T. Itoh, and K. Yokota, Polym. J., 20, 1041 (1988).

17. T. Hirabayashi, T. Kawazaki, and K. Yokoda, Polym. J., 22, 287 (1990).

18. W. Risse and R. H. Grubbs, Macromolecules, 22, 1558 (1989). 